\title{
PATTERNS OF MATING AND FECUNDITY IN SEVERAL COMMON GREEN LACEWINGS \\ (NEUROPTERA: CHRYSOPIDAE) OF EASTERN NORTH AMERICA*
}

\author{
By Charles S. Henry and Christine Busher \\ Box U-43, Dept. of Ecology and Evolutionary Biology \\ The University of Connecticut, 75 North Eagleville Road \\ Storrs, Connecticut 06268 (U.S.A.)
}

Recently, much interest and innovative research have focussed on the mating systems of animals (Thornhill and Alcock, 1983; Willson and Burley, 1983). Our interpretation and understanding of reproductive behavior, for example, has undergone a metamorphosis in the last few years. In the recent past, such common reproductive activities as courtship were viewed as steps to overcome some sort of physiological threshold in the female of the species (Marler and Hamilton, 1966, chapter 3), or, alternatively, as mechanisms to prevent the interbreeding (hybridization) of different species (Mayr, 1963). However, principally since the publication in the mid 1970's of works by Alexander $(1975,1977)$ and Wilson (1975), evolutionary biologists have adopted a rather different view of courtship and other reproductive behavior. This perspective is a more inclusive one, stressing the evolutionary or selective benefits to individuals of behaving the way they do during sexual activity. Courtship is more properly viewed as a series of test questions posed by the courting individual to its potential partner. The answers to these questions help the individual decide where the other individual is located; what species and sex that individual is, to avoid costly mistakes in mating; and how good a mate that individual will make, in terms of its vigor, strength, and success at intrasexual competition or at securing resources for its partner. In fact, the ultimate goal of reproductive behavior is success in transmitting an individual's genes to the next generation, through the production of viable, fit offspring.

Individual reproductive success can be achieved in a variety of ways. Females can have very high fecundity, or they may provide more care or resources for fewer offspring. Additional strategies are

*Manuscript received by the editor September 25, 1987 
open to males, which need only produce energetically "cheap" sperm rather than expensive eggs. On the one hand, a male can copulate with as many females as time and conditions allow; alternatively, he may be more careful to ensure, through attention and guarding, that the sperm transferred are actually used by the female to produce offspring (Waage, 1983). The stage is set in many animals for sexual inequality: males may embark on highly polygynous reproductive lives, while females choose fewer times and more carefully among the scrabbling suitors. With such inequities comes unfairness, especially among males: if one male can inseminate many females, but each female accepts only a few males, then many other males must never get the opportunity to mate. High variance in reproductive success among males is the basis for strong sexual selection on males (Darwin, 1859, 1871), which in turn is thought to sculpt the obvious morphological and behavioral dimorphism between the sexes that exists in the majority of animal species.

It is often assumed, but rarely documented, that individual males of sexually dimorphic species inseminate many females, and can produce many more progeny than can individual females. Conversely, it follows that species displaying little sexual dimorphism should be reasonably equivalent in the reproductive potential of the two sexes. Insects are well suited for testing predictions of sexual selection theory, because they exhibit inexhaustible diversity of lifehistory strategy (Dingle and Hegmann, 1982) and are often easy to observe and manipulate in the field and laboratory. For example, green chrysopid lacewings show a convenient range of sexual dimorphism, from extreme in Meleoma Fitch spp. (Bickley and MacLeod, 1956), through moderate in the common Chrysopa oculata Say (Smith, 1922), to negligible in the carnea-group within the genus Chrysoperla Steinmann (Henry, 1983). Fortunately, most lacewing species adapt well to laboratory culturing, so simple studies measuring individual reproductive success are both feasible and reasonably representative of conditions in nature. Here, we concentrate on the reproductive biology of two well known, closely related species of the carnea-group, but we include some preliminary data on several other species characterized by greater sexual dimorphism.

The principal protagonists are the sympatric, closely related North American species C. plorabunda (Fitch) and C. downesi (Smith). C. plorabunda is a common meadow-dwelling form with multiple generations per year, while $C$. downesi is a darker green 
conifer-associated species that produces but one annual generation (Tauber and Tauber, 1976; Henry, 1980a). Each species, but especially $C$. plorabunda, has been well studied because of its importance in biological control (New, 1975; Hassan, 1978). Also, both species have figured prominently in investigations of sympatric speciation through disruptive selection (Tauber and Tauber, 1977a, b; 1982) and song divergence (Henry, 1980a, 1983, 1985a, b). Extensive fecundity data, relating egg production to diet or age, have been published for these and several other important green lacewings (Rousset, 1983). However, the extent of polygyny and polyandry, or the effect of multiple matings on fertility and fecundity, have not been determined for any chrysopid. Yet such basic information about mating habits and consequences is prerequisite to understanding several broader issues-particularly, the consequences of different life-history patterns and reproductive strategies, the dynamics of rapid speciation through acquisition of assortative mating patterns (West-Eberhard, 1983; Henry, 1986), and mass rearing and release in programs of biocontrol.

\section{Methods ANd Materials}

Data for this paper were generated over several years, as part of a larger project investigating courtship singing behavior, reproductive isolation, and speciation in sibling species of the genus Chrysoperla (Henry, 1983, 1985a, b, 1986). Adult green lacewings of C. plorabunda, C. downesi, and several additional species were collected from the field during the warmer months and maintained throughout the year in small, outbred colonies of 25 to 50 individuals. Most species were available locally, within 15 miles of Storrs, Connecticut; however, C. downesi and most of the Meleoma emuncta (Fitch) came from coniferous forests on the E. N. Huyck Preserve in Rensselaerville, New York. Additional C. downesi in 1982 and 1983 were from populations in central Vermont (Echo Lake), southern New Hampshire (Mount Monadnock), and northwestern Massachusetts (north of Quabbin Reservoir). And late in 1986, we included several individuals of $C$. plorabunda from near Moscow, Idaho, in the study. Laboratory colonies of all species were maintained as described earlier (Henry, 1979, 1980a, b) and kept at $26 \pm 2^{\circ} \mathrm{C}$. An artificial diet consisting of equal proportions (by weight) of honey, yeast hydrolyzate $\left(\mathrm{Difco}^{\mathrm{TM}}\right)$, water, and $\mathrm{Wheast}^{\mathrm{TM}}$ was available in excess to all adults. Chrysopa oculata, the only species studied 
requiring adult prey for proper egg maturation (Tauber and Tauber, 1973), was given Aphis fabae Scopoli raised on greenhouse-grown Nasturtium sp. Meleoma emuncta adults were fed a mixture of assorted pollens and honey (J. Johnson, Univ. of Idaho, pers. com.). All larvae were fed ether-killed Drosophila spp. every 2-3 days. Photoperiod was manipulated for $C$. downesi to break adult reproductive diapause (Tauber and Tauber, 1976); for other species, constant long-day (17L:7D) light regimes were maintained.

We took three simple experimental approaches: (1) Fieldcaptured, gravid females were allowed to oviposit freely without re-mating. From this, we could assess the extent of egg productivity possible from sperm in reserve under natural conditions. (2) Young (two-week-old), laboratory-reared virgin females were mated as often as they would accept previously unmated males, while others of the same cohort were mated just once; whenever possible, copulation duration was noted. Egg production and sexual receptivity were monitored for each female throughout the experiment. This approach was designed to determine the extent of polyandry, the number of eggs produced per copulation, and the relationships among sexual receptivity, re-mating, copulation duration, and egglaying. Sexual receptivity, which is lost in female lacewings after copulation, was assessed by playing back species-appropriate songs to the insects and waiting for "answers" (abdominal dueting behavior [see Henry, 1985a, b]). To minimize the effects of aging on fecundity, insects that had been sexually mature for more than two weeks were excluded from these studies. Maturity, in turn, was judged by the onset of sexual receptivity. (3) Finally, individual two-week-old males were re-mated to unmated, receptive females at 1-3 day intervals, until they could no longer copulate. This provided estimates of sperm transferred and accepted per copulation, degree of polygyny, and minimum total lifetime reproductive potential for each male. Females were selected from cohorts of the same age as the males. Since a single male could easily mate with many females, we were forced in one case (male $\mathrm{H}$ of Table 6) to recruit two-weekold virgin females after the 18 th copulation.

All three approaches above shared one simple but important protocol: count every egg and determine whether or not it had been fertilized. Counting was facilitated by the egg stalk so typical of the green lacewings: each egg could be clipped cleanly from its substrate and placed on the filter paper floor of a $10 \mathrm{~cm}$ plastic petri dish for 
storage. Fertility was indicated by darkening of the initially green egg within two days of oviposition at about $26^{\circ} \mathrm{C}$. Unstalked eggs, glued directly to the substrate or dropped to the ground, were also monitored for darkening and included in any counts if fertile. Eggs were clipped, counted, and monitored three times per week, unless otherwise specified. Clipped eggs from one session were saved until the next, so that their fertility or sterility could be guaranteed. Since just 5 to 10 percent (at most) of any individual female's eggs were ever inviable, the results tabulate only fertile, developing eggs.

Sample sizes varied considerably from one experiment to another, due to the opportunistic nature of the studies. For example, egg counts were performed on 8 field-captured, gravid females of Chrysopa oculata and 6 of Chrysoperla harrisii (Fitch), but only three of such females of $C$. rufilabris (Burmeister) and one of $C$. downesi were available, and C. plorabunda was neglected altogether. Similarly, multiple-mating experiments on females were completed only with $C$. plorabunda (21 females) and C. downesi (17 females). Individuals that produced fewer than 400 eggs were excluded, since our interest was in maximal fecundities. Male multiple-mating studies were limited to $C$. plorabunda (8 males), $C$. downesi (2), and $C$. oculata (2). Finally, a few data correlating fertility with copulation duration were taken, but only for $C$. plorabunda (27 matings) and C. downesi (15 matings).

Means and standard deviations were calculated from the data using a computer spreadsheet (LOTUS $1,2,3^{\text {TM }}$ ). Samples were tested for normality by a Kolmogorov-Smirnov routine, and deemed significantly different by two-tailed t-tests and confidence limits of $99 \%$, using the statistical functions of the computer program ASYSTANT ${ }^{\mathrm{Tm}}$.

Voucher specimens have been deposited in the insect collection of the Department of Ecology and Evolutionary Biology, University of Connecticut, Storrs.

\section{RESULTS}

\section{Egg Counts: Field-captured, Gravid Females.}

Egg productivity by wild females of $C$. oculata, $C$. harrisii, $C$. rufilabris, $C$. downesi, and $M$. emuncta are shown in Tables 1 and 2 (no field-collected $C$. plorabunda were tested). For all species except M. emuncta, totals per female averaged between 700 and 1000 eggs: insignificantly different from one another. Such totals also reflect 


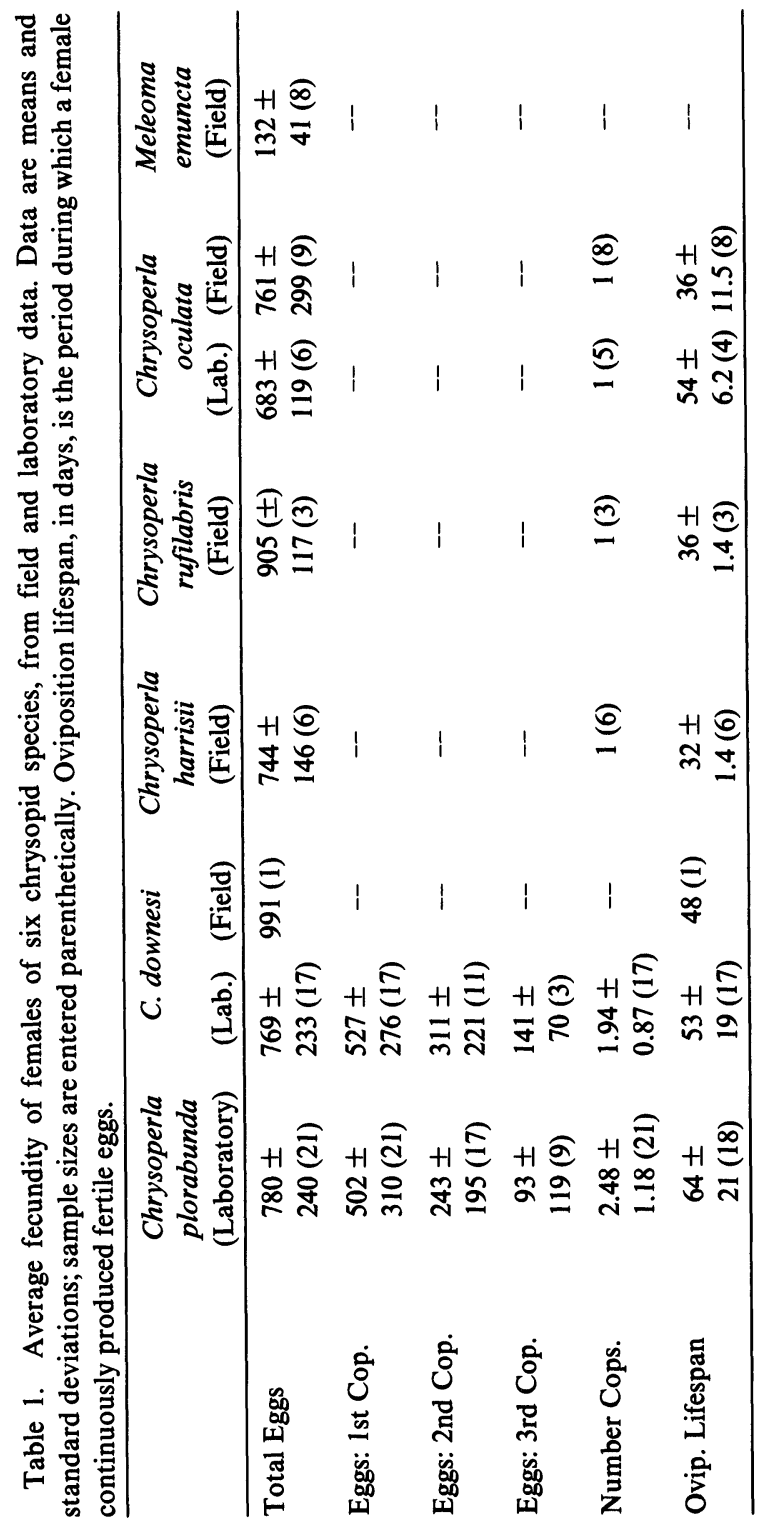


single-mating reproductive potentials of individuals of those species, because other experiments described elsewhere in this paper indicate that female lacewings do not store appreciable quantities of sperm from one mating to another. Certain field-caught individuals within each species were remarkably fecund, especially considering that none was re-mated after capture. For example, some females of $C$. oculata and C. rufilabris oviposited more than 1000 fertilized eggs, while one female each of $C$. harrisii and $C$. downesi nearly matched that level (Figs. 1, 3, Table 2). Except for slightly higher early rates of egg-laying by $C$. oculata, the overall patterns shown are quite similar in all of the above species, and in fact are much the same as that seen in monogamous $C$. plorabunda raised in the laboratory (Fig. 2). The egg production by all once-mated females of all species, whether laboratory-reared or field-captured, is summarized in Table 2.

\section{Egg Counts: Continuously Re-mated Females.}

The C. plorabunda and C. downesi females mated 1-6 times, the former species averaging a total of 780 eggs and the latter 769 (Tables 1, 3, and 4). Both species averaged two matings over an individual's lifespan. Oviposition spanned a mean of 64 days in C. plorabunda and 53 days in C. downesi, but the high variance indicates no significant interspecific difference.

Lifetime patterns of egg-laying, sexual receptivity, and mating varied considerably among individuals of both species. Some females produced consistently high numbers of eggs for prolonged periods from their first fertilization, without ever recovering sexual receptivity or re-mating. Examples of this pattern can be seen in both $C$. plorabunda (86-4, Fig. 2) and $C$. downesi (FLD1, Fig. 3). More commonly, a female became sexually receptive and re-mated after a shorter time, just as her egg productivity began to dip (Figs. 2,3 , Table 5). If immediately re-fertilized, such individuals oviposited large numbers of eggs again and receptivity disappeared, but without re-mating egg production soon ceased, suggesting sperm depletion. A third, rare subset of individuals recovered sexual receptivity many days before their egg productivity declined, as seen in females E (C. plorabunda) and B and E (C. downesi) in Table 5. Actually, receptivity in such insects waxed and waned rather erratically, and none succeeded in re-mating until egg production truly diminished. 


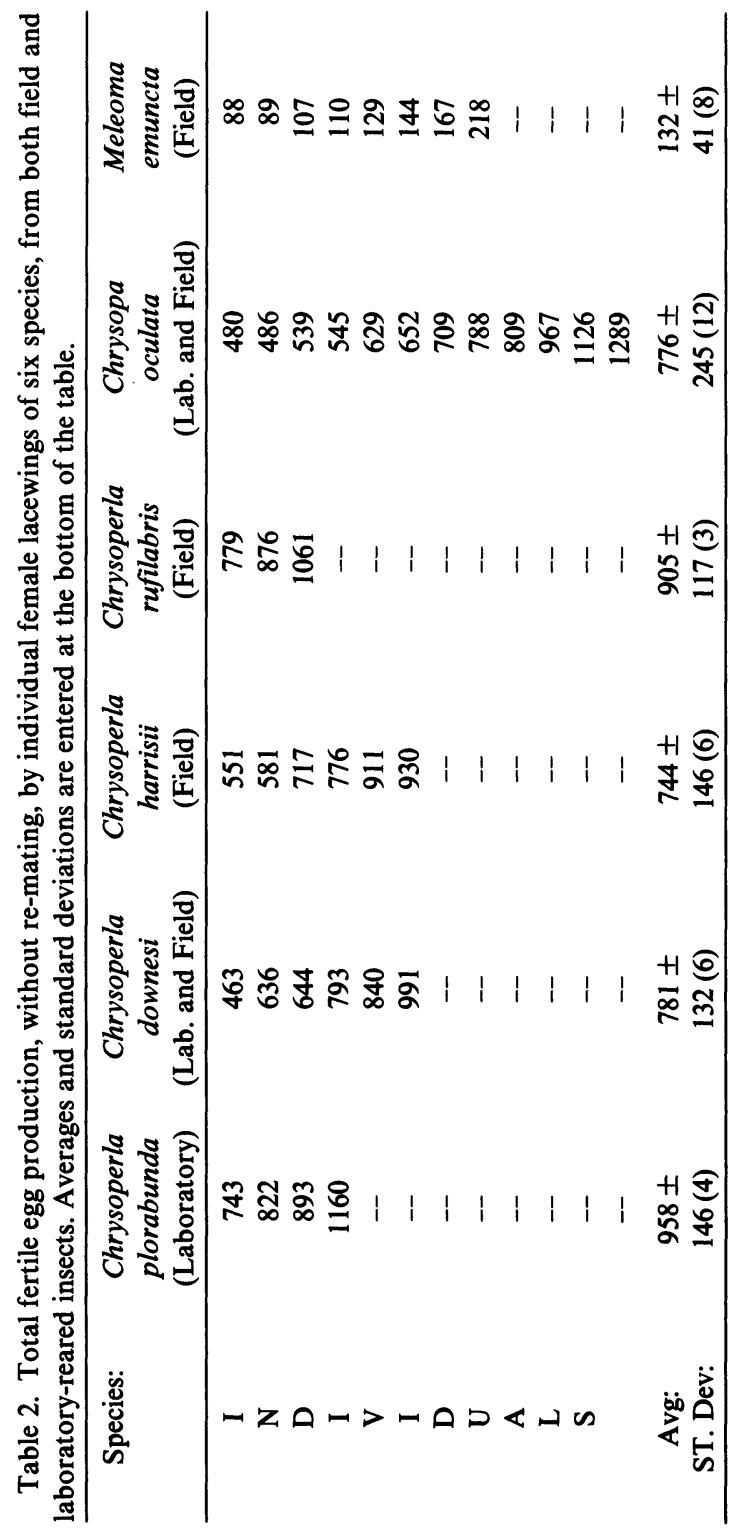


In general, females that mated more than once produced the majority of their eggs from the first copulation (Tables 3 and 4). However, a subsequent pairing could yield large numbers of eggs if earlier copulations had little issue (e.g., I, Table 3, and B, Table 4). At their peak of egg productivity, females of either species could oviposit nearly 40 eggs per day. Despite varying rates of egg-laying and radically different lifetime patterns of re-mating, the most fecund individuals consistently laid about 1200 eggs altogether.

Field-captured Meleoma emuncta females had the lowest fecundity of any of the lacewings studied (avg. 132 eggs/female, Table 2). This low fecundity may be due in part to unknown dietary or environmental requirements for optimal growth and reproduction (Tauber 1969); the species is notably difficult rear (J. Johnson, pers. com.).

\section{Male Reproductive Potential: Continuously Re-mated Males.}

Males of $C$. plorabunda, C. downesi, and C. oculata could mate several times (Table 6). One $C$. downesi mated with 10 different females at 24-hour intervals, and $C$. plorabunda males inseminated maxima of 22 and 30 females. The highest value was posted by an individual of $C$. plorabunda that was re-mated at 2-day rather than 24-hour intervals; in fact, this male remained reproductively competent for much of his long lifespan (210 days). Generally, the data from egg counts described a decline in male fertility with time, suggesting irreversible sperm depletion. However, the active individual was conspicuously different, maintaining high fertility even after many copulations: for example, his 20th female oviposited 620 eggs, as many as produced by females paired with fresh, virgin males. The reproductive potential of males consistently exceeded that of females in all three species studied. Again, the exceptional $C$. plorabunda male fathered many more offspring than any other individual: over 9600 , vs. 2253 for the runner-up. The performance of this extraordinary individual, compared with the next-mostfertile male, is graphed in Fig. 4.

Egg Production vs. Copulation Time.

Chrysoperla plorabunda had consistently shorter matings than its sibling, C. downesi (Table 7). Highest individual fecundity in the former species was associated with copulation durations of 8-10 minutes, whereas in C. downesi, longer copulations (19-65 minutes) 


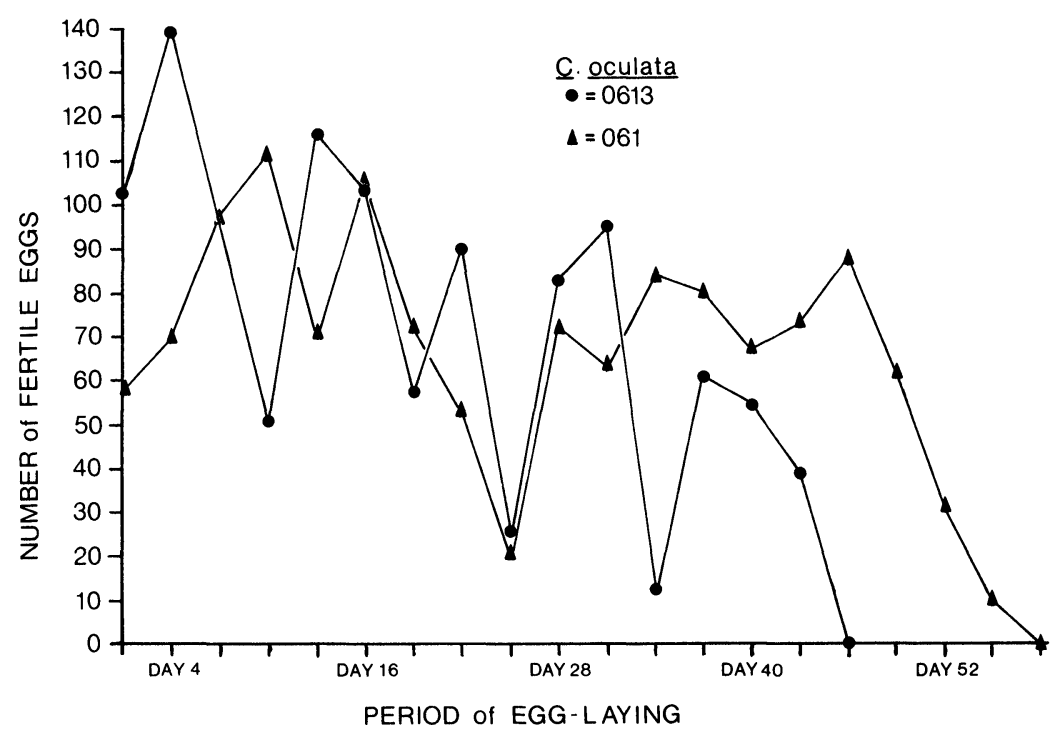

Figure 1. Fertile egg production as a function of time in two females of Chrysopa oculata, collected from the field. Eggs were clipped every 3 days.

were optimal. C. downesi varied considerably more than C. plorabunda in the time spent in copulo, although high variance typified both species.

\section{Discussion}

Female Fecundity.

Fecundity data on many lacewing species are well summarized in Rousset (1983). Our results differ strikingly from those of other workers, in the sheer numbers of eggs produced by individual lacewings under a variety of mating protocols. For example, even singlemated females of $C$. plorabunda, $C$. downesi, $C$. harrisii, $C$. rufilabris, and $C$. oculata produced 1000 or more fertile eggs (Table 2 ), which is significantly more than previously reported for any lacewing. Multiply-mated females increased this figure further, to 1207 in C. plorabunda and 1286 in C. downesi (Tables 3 and 4). (The champion was actually a single-mated $C$. oculata that deposited 1289 eggs in 55 days.) The literature reports individual maxima of only 617 for C. oculata (Smith, 1922), 850 for C. plorabunda $(=C$. carnea [Stephens]; Hagen and Tassan, 1966), and 189 for $C$. 


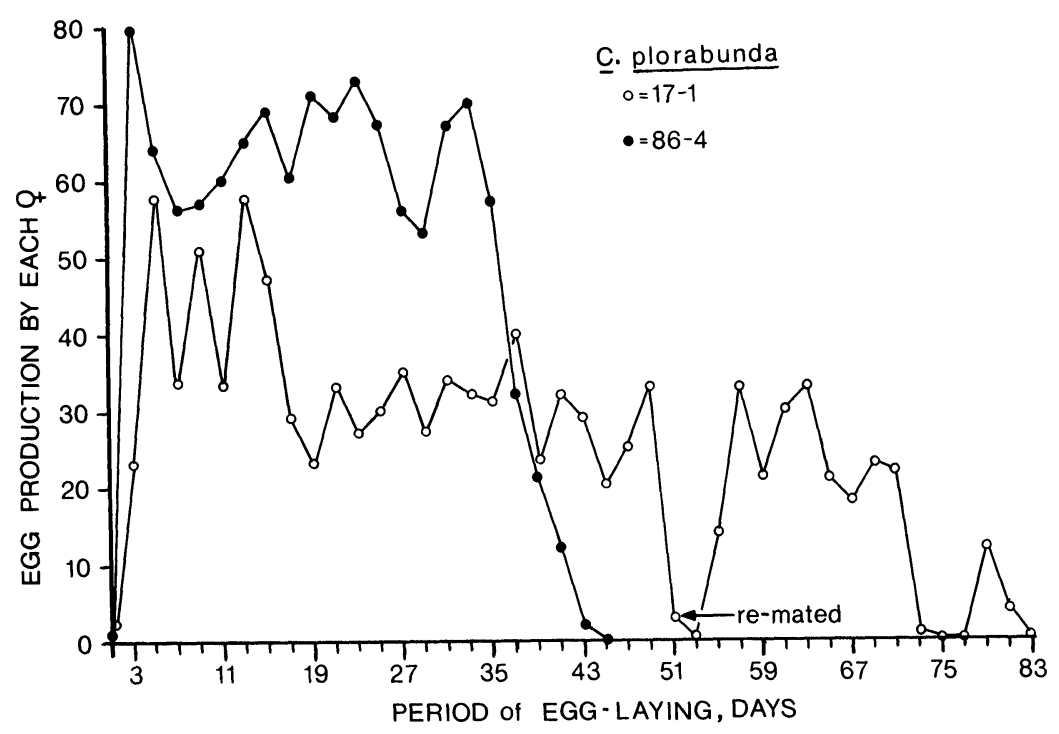

Figure 2. Fertile egg production as a function of time by two females of Chrysoperla plorabunda, mated in the laboratory on Day 1. Eggs were clipped on a 2, 2, and 3 day timetable each week.

rufilabris (Hydorn and Whitcomb, 1979; Ru et al., 1976), all reared on diets very similar to those we used. We are unable to explain these discrepancies, except to note that great variability characterizes the reproductive potential of lacewings of all species. Occasionally, for example, we found ourselves rearing a stock of insects with consistently low fecundity and high larval mortality, despite continuing efforts to avoid inbreeding. Whether such episodes were the results of genetic factors or disease was never resolved, but analogous problems could have unnaturally curbed egg productivity in the studies of others.

An important and perhaps unexpected result of this work was the observed uniformity of maximal individual egg production from species to species. On the one hand, it may not be too surprising to find similar maximal fecundities in very closely related, sibling species like $C$. plorabunda and $C$. downesi; but more distantly related taxa like $C$. rufilabris and $C$. harrisii and even representatives of distinct genera like Chrysopa oculata also had similar individual lifetime egg totals. Actually, even the life-history patterns of the 


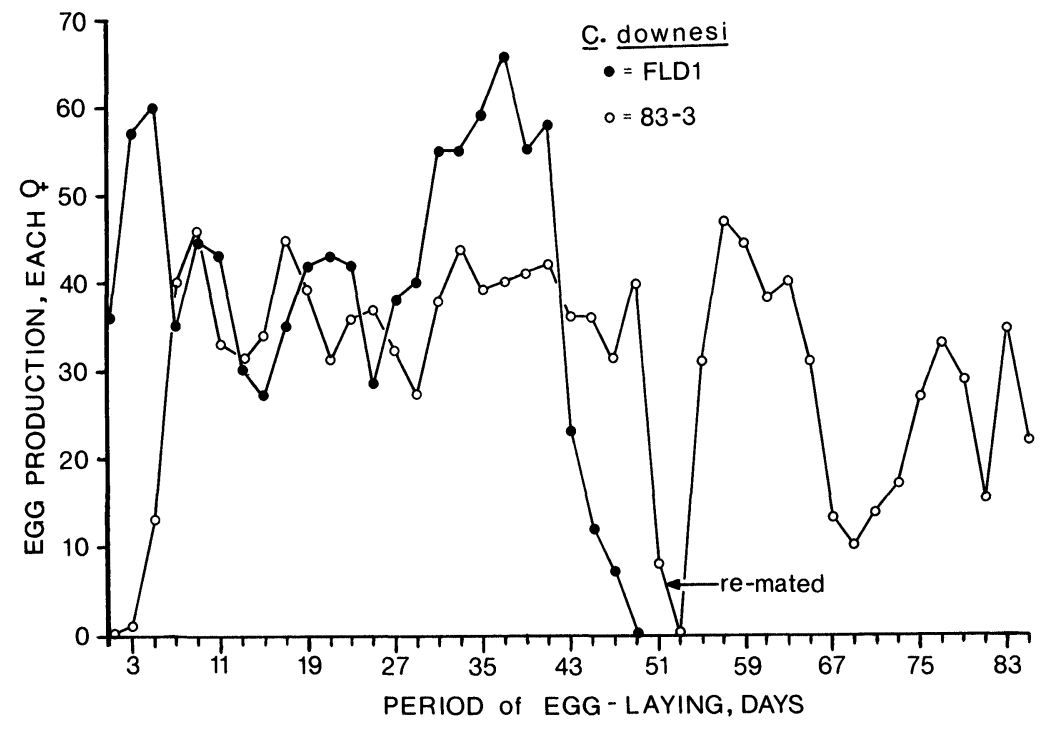

Figure 3. Fertile egg production as a function of time for two females of Chrysoperla downesi, mated on day 1 (83-3) or collected from field (FLD1). Eggs were clipped on a 2, 2, and 3 day timetable each week.

siblings $C$. plorabunda and $C$. downesi differ so much that their similar fecundities seem anomalous: the former species is multivoltine, whereas the latter is univoltine. In any case, it seems clear that individual females of either C. plorabunda or C. downesi can fertilize about 80 percent of their lifetime supply of viable eggs with the sperm of a single male, although this may not happen very often in nature, for reasons to be discussed shortly. Principi (1949) obtained similar results for $C$. formosa Brauer, suggesting that a fertilization pattern like this may be widespread in Chrysopidae. Females in some other insect orders have also been shown to fertilize most of their eggs with the sperm of their first mate: Drosophila melanogaster Meigen is a good example (Pyle and Gromko, 1978).

The relatively low fecundity of Meleoma emuncta (Table 2) may not be typical of the species or genus, for Tauber (1969) counted 347 fertile eggs from one female fed an artificial diet fortified with levulose and choline chloride. In that study, a specimen of $M$. dolichartha (Navas) produced 313 eggs from the same diet. As mentioned 


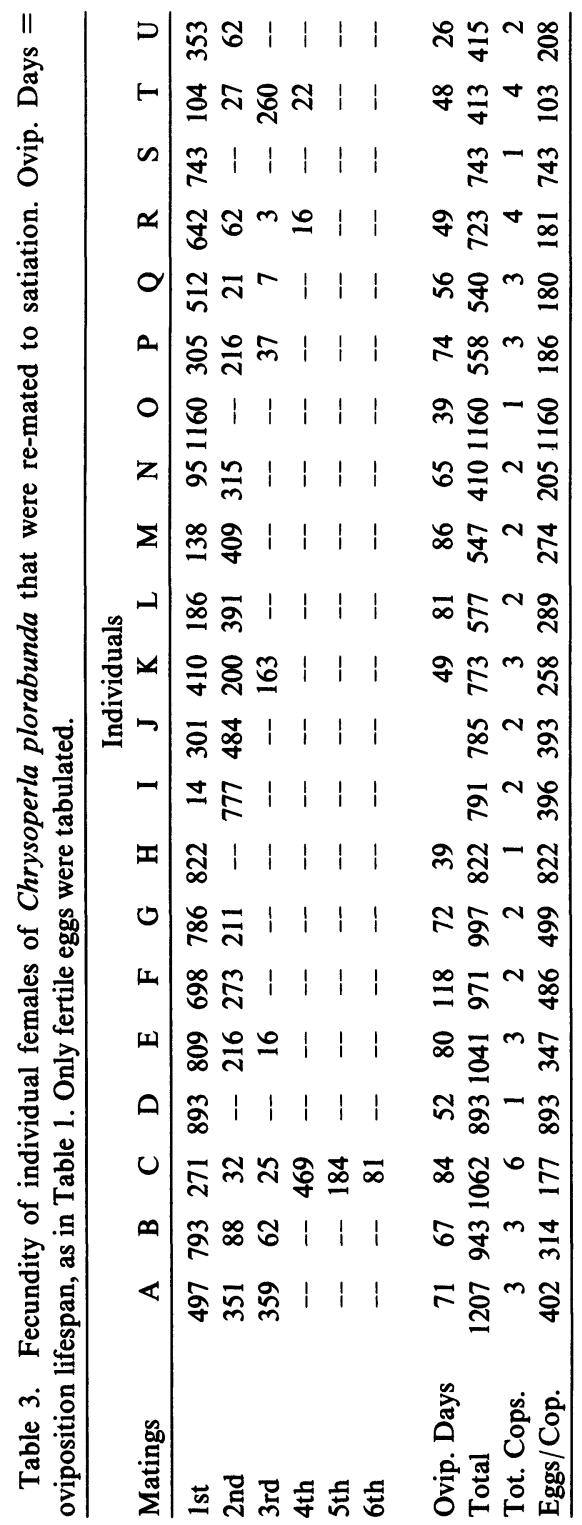




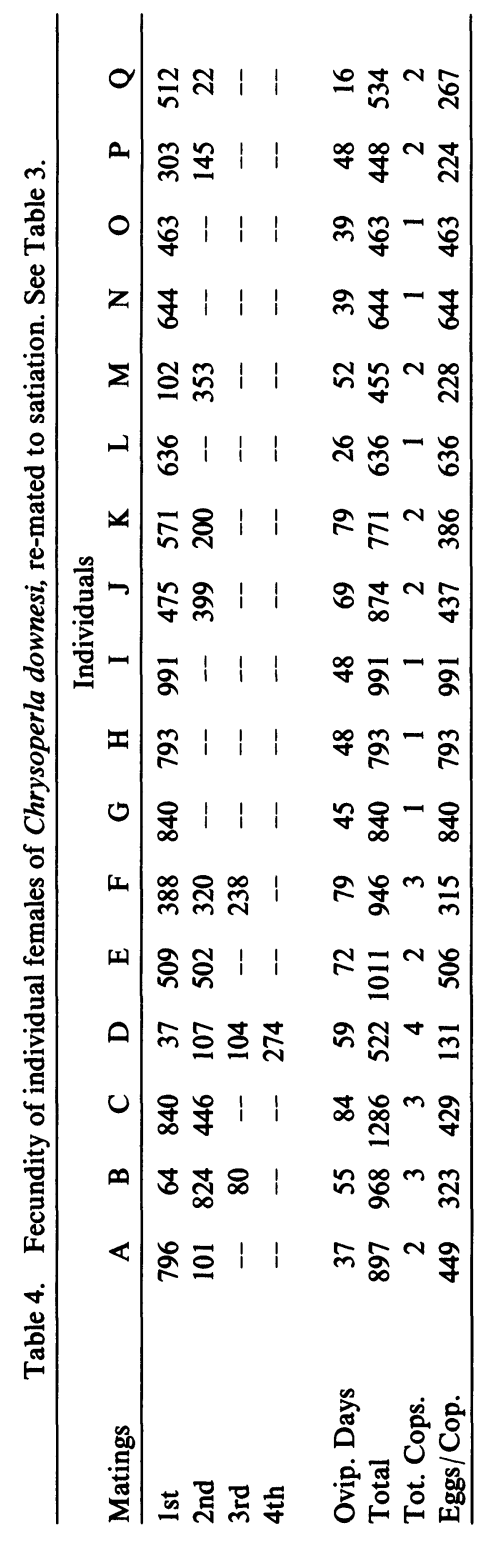




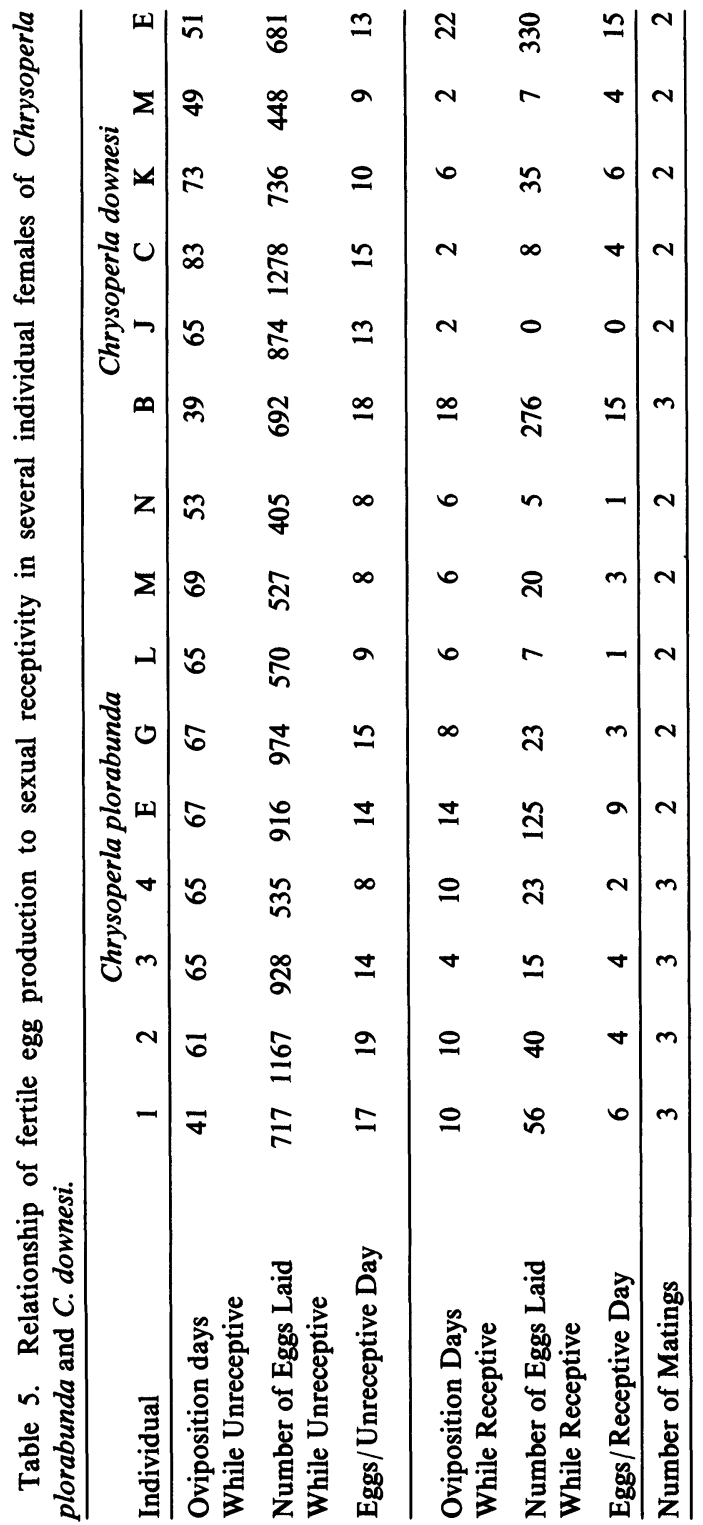




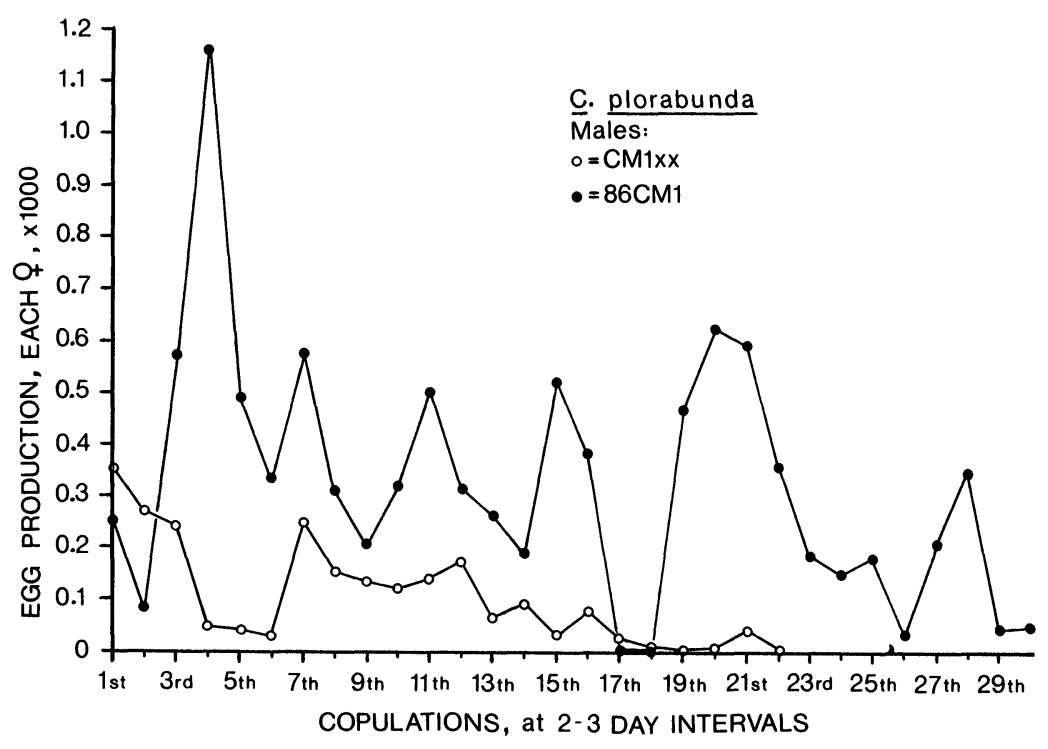

Figure 4. Total fertile egg production by the successive mates of two males of $C$. plorabunda, mated every 2 days (CM1xx) or every 2-3 days (86CM1). Young females were made available to $86 \mathrm{CM} 1$ after his 18 th copulation.

earlier, species of Meleoma often have specialized dietary or photoperiod requirements that can complicate any measurements of fecundity. Actually, the number of eggs produced by females employed in our study was undoubtedly higher, because we cannot assess the number laid in the field prior to capture.

\section{Female Polyandry.}

It has long been known that female lacewings will mate more than once. Smith (1922) observed this in C. oculata, and second matings have been tabulated for European C. perla (L.) by Philippe (1971) and C. plorabunda by Jones et al. (1977), among others. The present study documents for $C$. plorabunda and $C$. downesi just how often a female will re-mate. Unlike many other insects-such as damselflies (Waage, 1983), scorpionflies (Thornhill, 1980), and crickets (Loher and Rence, 1978)-these green lacewings lose sexual receptivity after mating, and must nearly exhaust their stored supply of sperm before copulating again. Alternatively, it may be that stored sperm dies or is discarded by the female, or in some other way becomes unavailable to her; but the simplest explanation of our results is that 
sperm gets used up. As seen in Figs. 2 and 3 and Table 5, receptivity and re-mating are strongly correlated with dips in egg production, after which oviposition increases again to earlier levels. That the new surge of egg production is the result of and uses the new sperm is supported by two cases in which $C$. downesi females, originally mated to conspecifics, were later mated to C. plorabunda males; the new offspring were all $F_{1}$ hybrids with typical $F_{1}$ hybrid song phenotypes.

The extent of polyandry in these insects reflects the interaction of three factors: rate of egg-laying, number of usable sperm transferred from the male, and oviposition lifespan. Our data indicate that maximal rates of egg-laying and maximum oviposition lifespan are approximately equivalent in all lacewing species studied to date. For example, females in peak condition produce 40-60 eggs per day; field-captured C. oculata, C. rufilabris, and C. harrisii show generally higher values than laboratory-raised $C$. plorabunda or $C$. downesi (Table 1). Reports from the literature are more or less similar, ranging from the 20-40 eggs per night cited by Tassan $e t$ al. (1979) and Duelli (1981) for C. plorabunda, to the 48 per night mentioned by Ickert (1968) for C. perla. Similarly, oviposition duration is approximately the same in both $C$. plorabunda and $C$. downesi regardless of sperm availability (but is irretrievably diminished by senescence even in virgin females after two or at most three months; see Table 5). In contrast, the quantity of sperm contributed per copulation, interpolated from fecundity measured between matings, shows high variance, and may be the principal determinant of polyandry. Females that chance to receive relatively little sperm with successive copulations will repeatedly recover sexual receptivity and re-mate, whereas those receiving large amounts of sperm early in life will live out a significant or even dominant portion of their allotted reproductive lives depositing eggs fertilized by their first partners. Thus, the most frequently mated females like $\mathrm{C}$ and $\mathrm{T}$ of Table 3 and $D$ of Table 4 produced only a few viable offspring from early inseminations. Female senescence can be seen most clearly when older, virgin females are mated to fresh males: invariably, egg production is significantly less than that of younger ones. At least some of the wide variance in fecundity can be attributed to age differences at first copulation. We found little evidence to support Philippe's (1971) suggestion, concerning C. perla, that sperm from each copulation fertilizes the eggs produced during a relatively constant number of oviposition days: in his study, 24. 
In many ways, female polyandry in lacewings is much like that in Drosophila, particularly $D$. melanogaster. These females re-mate a few times during their lifetimes, but often fertilize most of their eggs with the sperm of one male (Pyle and Gromko, 1978). In D. melanogaster, about $78 \%$ of the sperm must be depleted before the female will re-mate (Ibid.). And although a female's total complement of eggs can in theory be fertilized from one copulation, multiple matings nonetheless increase lifetime egg productivity by a small but significant amount (Gromko et al. 1984). These flies, like lacewings, achieve such fecundity patterns by a similar mechanism: females totally lose sexual receptivity after copulating, and regain it only when stored sperm has been nearly depleted.

Male Polygyny.

The results of the male multiple-mating experiments are the most difficult to interpret (Table 6, Fig. 4). For the most part, individual males of $C$. plorabunda and $C$. downesi showed a rather steep decline in their ability to inseminate females with successive matings. Both tested males of $C$. downesi conform to this pattern, so that after two or three matings, they were unable to father more than a few progeny, even though each mated 10 times. Similarly, most of the 8 C. plorabunda males appeared to run low on sperm after a series of consecutive matings; for these and the $C$. downesi "normal" males, reproductive potential was only slightly greater than that of females, averaging between 1000 and 2000 progeny over a lifetime (Table 6). However, one male of C. plorabunda sired over 9600 offspring during his 3.5 month reproductive life, mating 30 times. What appears to be a decline in his fertility at the time of his 17 th and 18th matings actually reflects the old age of the females used as his mates; once younger partners were recruited, postcopulation fecundity increased to levels nearly as high as those recorded early in the male's life (Fig. 4). Of course, it can be argued that data based on so few males are of little use. However, we were not so much concerned with average male mating performance and fertility as we were with maximal values, to determine whether individual males could inseminate many females and sire several thousands of offspring. Consequently, the results here can only underestimate the real reproductive potential of males of these species; a single vigorous, prolific individual is sufficient to highlight the differences between males and females. 
In many insects, especially Lepidoptera, spermatogenesis is completed before adulthood (Chen and Graves, 1970; Chaudbury and Raun, 1966; Retnakaran, 1970; Jumper and Cannon, 1975). Other insects continue manufacturing sperm as adults, e.g., Coleoptera (Jumper and Cannon, 1975; Chang and Riemann, 1967); or cockroaches, like Nauphaeta cinerea (Olivier) (C. Busher, pers. obs.). Although no experiments have confirmed this, it seems reasonable to assume that insects that continue to produce sperm through their adult lives should be capable of manufacturing more of it than those endowed with a fixed quantity at adult eclosion. Research on spermatogenesis in green lacewings has not addressed this issue. Some data for C. plorabunda suggest a lepidopteran, fixed-quantity pattern (Sheldon and MacLeod, 1974; Jones et al., 1977), and other studies on $C$. perla imply adult maturation and possibly adult manufacture of sperm (Philippe, 1970, 1972). It is known that individual spermatozoans in lacewings of Chrysoperla, Anisochrysa, and Chrysopa are quite large, measuring nearly $1 \mathrm{~mm}$ in length (Baccetti et al., 1969; Rousset, 1983). Considering how much space 9000 long sperm would occupy, our results with male 86CM1 $(=\mathrm{H}$ of Table 6$)$ strongly suggest continuous, on-demand sperm manufacture, at least in C. plorabunda and its close relatives.

These findings bear directly on the significance of sexual selection in lacewing species. Clearly, the potential is present for intense, asymmetrical sexual selection among males, because individual reproductive potential is so much higher in males than in females. In theory, a mere handful of males could monopolize the reproductive activities of a large number of females. If a given male could easily locate the receptive females in the area, and if those females had a way of choosing certain males over others, then he could experience disproportionately high reproductive success by either appealing to females or outcompeting other males. In nature, however, the situation is probably very different. Within a group of individuals living in close proximity, a male would most often encounter previously inseminated females that were unreceptive to his courtship songs. Secondly, males of Chrysoperla spp. are unable to call rare receptive females to them over long distances: their songs carry only centimeters, between individuals on contiguous substrates (Henry, 1980a). Thirdly, any male that can duet with a female is acceptable to her if she is sexually receptive (Henry, 1979, 1983, 1985a, b, 1986). 


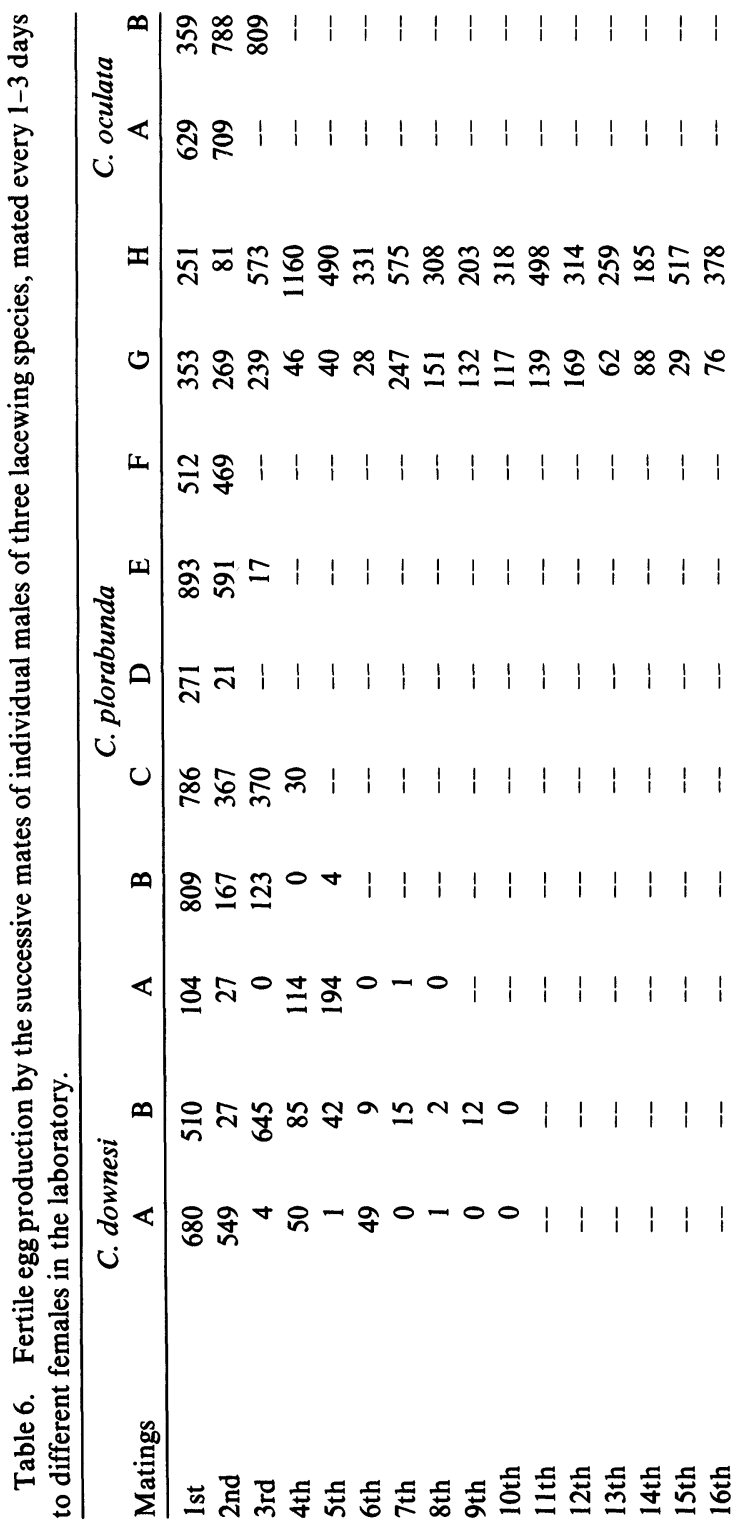




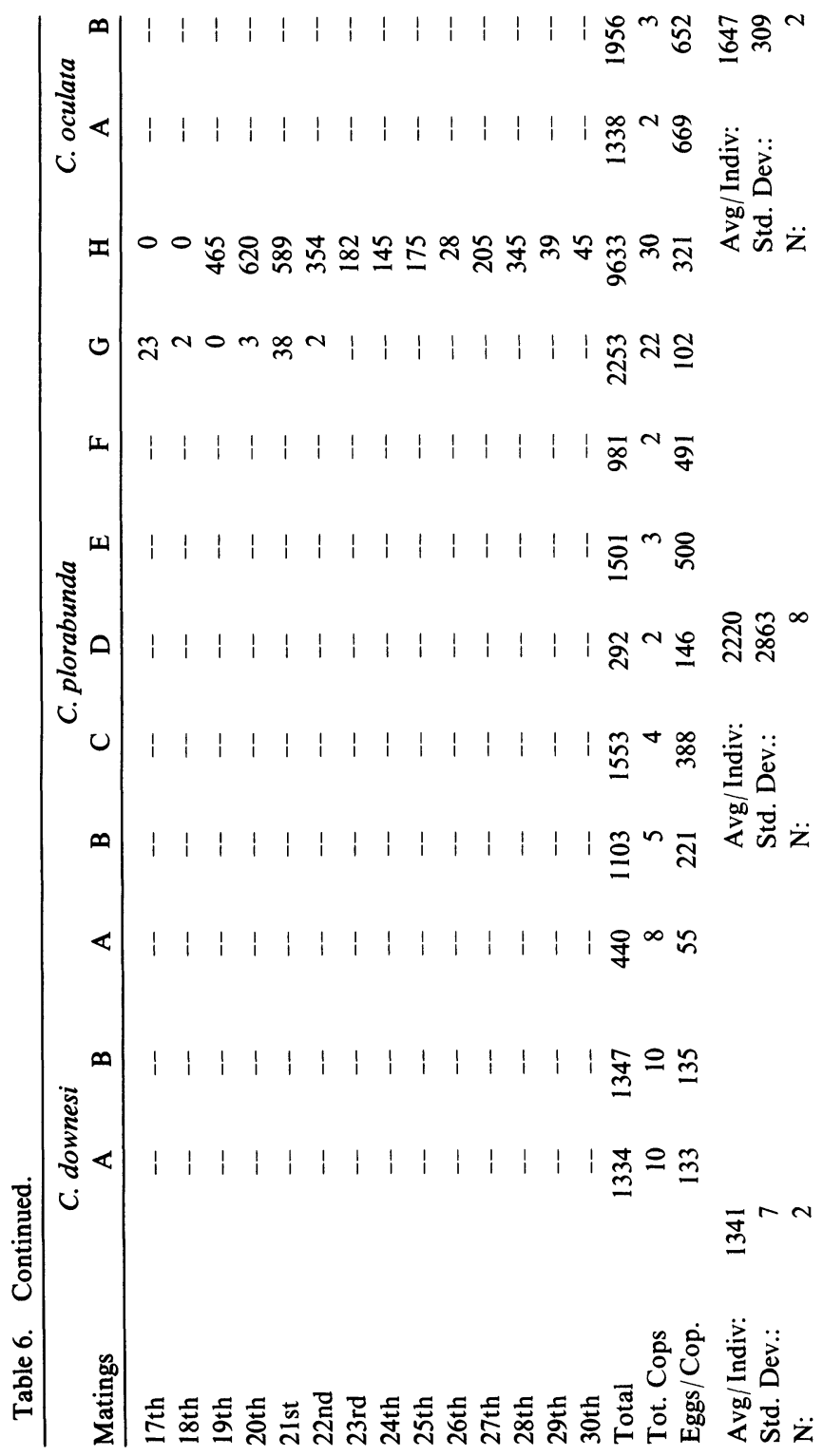


Finally, field experience tells us that individual lacewings are moderately dispersed rather than tightly clumped in space, so that rarely if ever will two males be present to compete for the privilege of mating with a receptive female. For that matter, even in the laboratory under conditions designed to encourage such competition, males never interfere with and barely even notice one another's courtship activities. As a consequence, we feel it likely that reproductive success is reasonably egalitarian among healthy males, despite their potential as individuals for high sperm production and multiple copulations. Thus, the intensity of sexual selection is little different for males than for females of Chrysoperla of the carneagroup, for reasons first clearly outlined in Emlen and Oring's important review (1977) of environmental influences on mating systems. Sexual dimorphism, which is coupled to the degree of asymmetry of sexual selection, is minimal in these species, as expected from the above argument (although see Hafernik et al. [1986] for a discussion of sexual dimorphism without sexual selection).

\section{General Conclusions.}

The same basic patterns of reproductive biology characterize all the green lacewings of this study. In the future, sexually dimorphic taxa should be studied; here, we have concentrated on a sexually monomorphic genus, Chrysoperla. In this genus, lifetime fecundity is high and reasonably equivalent in several common species. Polygamy of both males and females is the rule, although females can fertilize most of their eggs with sperm acquired from one copulation. Sexual receptivity mediates re-mating in females, and is only recovered when stored sperm is nearly depleted or otherwise unavailable. The time between matings varies greatly with the success of insemination; because sperm must be almost used up by egglaying before re-mating occurs, one is forced to the conclusion that males transfer variable quantities of sperm to different females. The causes of such variability in a given male are unknown, since the success of insemination shows no reliable correlations with either the number of previous matings or the duration of copulation. Potential for lifetime reproduction is much higher for males than for females because males can produce nearly unlimited quantities of sperm, but this potential probably goes unrealized in nature, because males have no reliable way of finding the few sexually 
Table 7. Fertile egg production versus copulation duration characterizing 27 individual females of Chrysoperla plorabunda and 15 of $C$. downesi.

\begin{tabular}{cccccc}
\hline \multicolumn{5}{c}{ Chrysoperla plorabunda } \\
Dura. & $5-7$ min & $8-10$ min & $11-13$ min & $14-18$ min & $19-65$ min \\
\hline Number & 9 & 271 & 114 & 27 & -- \\
of & 14 & 305 & 119 & 104 & -- \\
Eggs & 85 & 351 & 166 & 168 & -- \\
Laid & 102 & 698 & 353 & 194 & -- \\
Per & 301 & 786 & 410 & -- & -- \\
Individual & 387 & 793 & 512 & -- & -- \\
After & 484 & 809 & -- & -- & -- \\
Mating & 743 & 893 & -- & -- & -- \\
& 777 & -- & -- & -- & -- \\
\hline & & & Chrysoperla downesi & & \\
Dura. & $5-7$ min & $8-10$ min & $11-13$ min & $14-18$ min & $19-65$ min \\
\hline Eggs & -- & 54 & 512 & 9 & 21 \\
per & -- & 463 & 796 & 27 & 64 \\
Individual & -- & -- & -- & 138 & 161 \\
after & -- & -- & -- & 171 & 644 \\
Mating & -- & -- & -- & 303 & 824 \\
& -- & -- & -- & -- & 840 \\
\hline
\end{tabular}

receptive females in a population at a given time. The resulting approximate equality of sexual selection in the two sexes encourages low sexual dimorphism, as observed, although we acknowledge that there can be other causes of slight sexual dimorphism. Further speculation on subtle strategies of mate choice or sperm rejection by females or of sperm competition within the female's storage system should probably await experiments to test specific hypotheses.

\section{ACKNOWLEDGMents.}

This study was supported in part by National Science Foundation award BSR-8508080 to the first author and by the Research Foundation of the University of Connecticut. We thank Jane O'Donnell, William Cook, Raymond Pupedis, Carrie Toth, Julie Weber, and Gary Zanauskas, all presently or formerly of the University of Connecticut, for help in collecting and maintaining living lacewings. Our thanks are also extended to the staff of the E. N. Huyck Preserve, Rensselaerville, N.Y., for permission to collect at that site, and to 
James Johnson, University of Idaho, for sending live material from western North America. Carl Schaefer (University of Connecticut) unsparingly criticized and edited an early version of the manuscript, and two anonymous reviewers made additional helpful suggestions.

\section{References Cited}

Alexander, R. D. 1975. Natural selection and specialized chorusing behavior in acoustical insects. In D. Pimetel, ed., Insects, Science and Society. Academic Press, N.Y., N.Y.: 395 pp.

Alexander, R. D. 1977. Evolution, human behavior, and determinism. Proceedings Biennial Meeting of the Philosophy of Science Association (1976) 2: 3-21.

Baccetti, B., R. Dallai and F. Rosati. 1969. The spermatozoa of Arthropoda. 3. The lowest holometabolic insects. J. Microsc., Paris 8: 233-248.

Bickley, W. E. AND E. G. MacLeod. 1956. A synopsis of the nearctic Chrysopidae with a key to the genera (Neuroptera). Proc. Entomol. Soc. Wash. 58: 177-202.

Chang, T.-H. and J. G. Riemann. 1967. H3-Thymidine radioautographic study of spermatogenesis in the boll weevil Anthonomus grandis (Coleoptera: Curculionidae). Ann. Entomol. Soc. Am. 60: 975-979.

Chaudbury, M. F. B. and E. S. Raun. 1966. Spermatogenesis and testicular development of the European corn borer Ostrinia nubilalis (Lepidoptera: Pyraustidae). Ann. Entomol. Soc. Am. 59: 1157-1159.

Chen, G. T. AND J. B. Graves. 1970. Spermatogenesis of the tobacco hornworm (Lepidoptera: Sphingidae). Ann. Entomol. Soc. Am. 63: 1095-1104.

Darwin, C. 1859. On the Origin of Species by Means of Natural Selection. 6th edition. Murray, London.

Darwin, C. 1871. The Descent of Man, and Selection in Relation to Sex. Modern Library, New York, N.Y.

Dingle, H., and J. P. Hegmann (eds.). 1982. Evolution and Genetics of Life Histories. Springer-Verlag, New York, N.Y.

Duelli, P. 1981. Ein funktionelles Konzept fur die Begriffe Dispersal und Migration, dargestellt anhand der Ausbreitungs bynamik der Florfliege Chrysopa carnea. Mitt. Dt. Ges. Allg. Angew. Entomol. 3: 49-52.

Emlen, S. T. AND L. W. Oring. 1977. Ecology, sexual selection, and the evolution of mating systems. Science 197: 215-223.

Gromko, M. H., D. G. Gilbert and R. C. Richmond. 1984. Sperm transfer and use in the multiple mating system of Drosophila. In R. L. Smith, editor, Sperm Competition and the Evolution of Animal Mating Systems, pp. 371-426. Academic Press, New York, N.Y. 687 pp.

HAFERNiK, J. E., JR. AND R. W. GARRISON. 1986. Mating success and survival rate in a population of damselflies: results at variance with theory? Am. Nat. 128: 353-365.

HAGEN, K. S. AND R. L. TASSAN. 1966. The influence of protein hydrolysates of yeast and chemically defined diet upon the fecundity of Chrysopa carnea Steph. Vest Csl. Spol. Zool. 30: 219-227. 
Hassan, S. A. 1978. Releases of Chrysopa carnea Steph. to control Myzus persicae (Sulzer) on eggplant in small greenhouse plots. Z. PflKrankh. PflPath. Pf1Schutz 85: 118-123.

HenRY, C. S. 1979. Acoustical communication during courtship and mating in the green lacewing Chrysopa carnea (Neuroptera: Chrysopidae). Ann. Entomol. Soc. Am. 72: 68-79.

Henry, C. S. 1980a. The courtship call of Chrysopa downesi Banks (Neuroptera: Chrysopidae): Its evolutionary significance. Psyche 86: 291-297.

HenRY, C. S. 1980b. The importance of low-frequency, substrate-borne sounds in lacewing communication (Neuroptera: Chrysopidae). Ann. Entomol. Soc. Am. 73: 617-621.

Henry, C. S. 1983. The sexual behavior of green lacewings. In M. Canard and Y. Semeria, eds., Biology of Chrysopidae, pp. 101-110. W. Junk, The Hague. $294 \mathrm{pp}$.

Henry, C. S. 1985a. Sibling species, call differences, and speciation in green lacewings (Neuroptera: Chrysopidae: Chrysoperla). Evolution 39: 965-984.

HenRy, C. S. 1985b. The proliferation of cryptic species in Chrysoperla green lacewings through song divergence. Fla. Entomol. 68: 18-38.

Henry, C. S. 1986. Good vibrations. Natural History 95: 46-53.

Hydorn, S. B., ANd W. H. Whitcomb. 1979. Effects of larval diet on Chrysopa rufilabris. Fla. Entomol. 62: 293-298.

ICKERT, G. 1968. Beitrage zur Biologie einheimischer Chrysopiden (Planipennia, Chrysopidae). Entomol. Abh. Mus. Tierk. Dresden 36: 123-192.

Jones, S. L., P. D. Lingren, AND M. J. BeE. 1977. Diel periodicity of feeding, mating and oviposition of adult Chrysopa carnea. Ann. Entomol. Soc. Am. 70: 43-47.

Jumper, G. A. AND W. N. CANnon. 1975. Spermatogenesis in the smaller European elm bark beetle Scolytus multistriatus (Coleoptera: Scolytidae). Ann. Entomol. Soc. Am. 68: 733-740.

LOHER, W. AND B. Rence. 1978. The mating behavior of Teleogryllus commodus (Walker) and its central and peripheral control. Zeitschr. Tierpsychol. 49: 225-259.

Marler, P. AND W. J. Hamilton, III. 1966. Mechanisms of Animal Behavior. Wiley, New York, N.Y. 453 pp.

MaYr, E. 1963. Animal Species and Evolution. Belknap Press of Harvard Univ. Press, Cambridge, Mass. 797 pp.

New, T. R. 1975. The biology of Chrysopidae and Hemerobiidae (Neuroptera) with reference to their usage as biocontrol agents: a review. Trans. Roy. Entomol. Soc. Lond. 127: 115-140.

Philippe, R. 1970. Role de la glande annexe lors de la ponte chez Chrysopa perla (L.) (Insectes, Planipennes). C. R. Hebd. Seanc. Acad. Sci. (Paris) 270: 2448-2450.

Philippe, R. 1971. Influence de l'accouplement sur le comportement de ponte et la fecondite chez Chrysopa perla (L.) (Insectes, Planipennes). Ann. Zool. Ecol. Anim. 3: 443-448.

Philippe, R. 1972. Biologie de la reproduction de Chrysopa perla (L.) (Neuroptera: Chrysopidae) en fonction de l'alimentation imaginale. Ann. Zool. Ecol. Anim. 4: 213-227. 
Principi, M. M. 1949. Contributi allo studio dei neurotteri italiani. 8. Morfologia, anatomia e funzionamento degli apparati genitali nel gen. Chrysopa Leach (Chrysopa septempunctata Wesm. e Chrysopa formosa Brauer). Boll. Ist. Entomol. Univ. Bologna 171: 316-362.

Pyle, D. W. And M. H. Gromko. 1978. Repeated mating by female Drosophila melanogaster. The adaptive importance. Experientia 34: 449-450.

Retnakaran, A. 1970. The male reproductive system of the spruce budworm, Choristoneura fumiferana (Lepidoptera: Tortricidae). I. Spermatogenesis. Ann. Entomol. Soc. Am. 63: 851-858.

Rousset, A. 1983. Reproductive physiology and fecundity. In M. Canard and Y. Semeria, eds., Biology and Chrysopidae, pp. 116-129. W. Junk, The Hague. 294 pp.

Ru, N., W. H. Whitcomb, AND M. Murphey. 1976. Culturing of Chrysopa rufilabris (Neuroptera, Chrysopidae). Fla. Entomol. 59: 21-26.

Sheldon, J. K. AND E. G. MACLeod. 1974. Studies on the biology of the Chrysopidae. 5. The developmental and reproductive maturation rates of Chrysopa carnea (Neuroptera, Chrysopidae). Entomol. News 85: 159-169.

Smith, R. C. 1922. The biology of the Chrysopidae. Mem. Cornell Univ. Agric. Expt. Stn. 58: 1287-1372.

Tassan, R. L., K. S. Hagen, and E. F. Sawall. 1979. The influence of field food sprays on the egg production rate of Chrysopa carnea. Environ. Entomol. 8: 81-85.

TAuber, C. A. 1969. Taxonomy and biology of the lacewing genus Meleoma (Neuroptera, Chrysopidae). Univ. Calif. Publs. Entomol. 58: 1-94.

TAuber, C. A. AND M. J. TAuber. 1977a. A genetic model for sympatric speciation through habitat diversification and seasonal isolation. Nature 268: 702-705.

Tauber, C. A. AND M. J. Tauber. 1977b. Sympatric speciation based on allelic changes at three loci: evidence for natural populations in two habitats. Science 197: $1298-1300$.

TAuber, C. A. AND M. J. TAuber. 1982. Evolution of seasonal adaptations and life history traits in Chrysopa: response to diverse selective pressures. In $\mathbf{H}$. Dingle and J. P. Hegmann, eds., Evolution and Genetics of Life Histories, pp. 51-72. Springer Verlag, New York, N.Y.

TAuber, M. J. and C. A. Tauber. 1973. Dietary requirements for mating in Chrysopa oculata (Neuroptera, Chrysopidae). Can. Entomol. 105: 79-82.

Tauber, M. J. AND C. A. TAuber. 1976. Developmental requirements of the univoltine species Chrysopa downesi: photoperiodic stimuli and sensitive stages. J. Insect Physiol. 22: 331-335.

Thornhill, R. 1980. Sexual selection in the black-tipped hangingfly. Sci. Am. 242: $162-172$.

Thornhill, R. And J. Alcock. 1983. The Evolution of Insect Mating Systems. Harvard Univ. Press, Cambridge, Mass. 547 pp.

WAAGE, J. K. 1983. Sexual selection, ESS theory and insect behavior: some examples from damselflies (Odonata). Fla. Entomol. 66(1): 19-31.

WeSt-Eberhard, M. J. 1983. Sexual selection, social competition, and speciation. Quart. Rev. Biol. 58(2): 155-182.

Willson, M. F., ANd N. Burley. 1983. Mate Choice in Plants. Princeton Univ. Press, Princeton, New Jersey.

Wilson, E. O. 1975. Sociobiology: The New Synthesis. Harvard Univ. Press, Cambridge, Mass. $697 \mathrm{pp}$. 

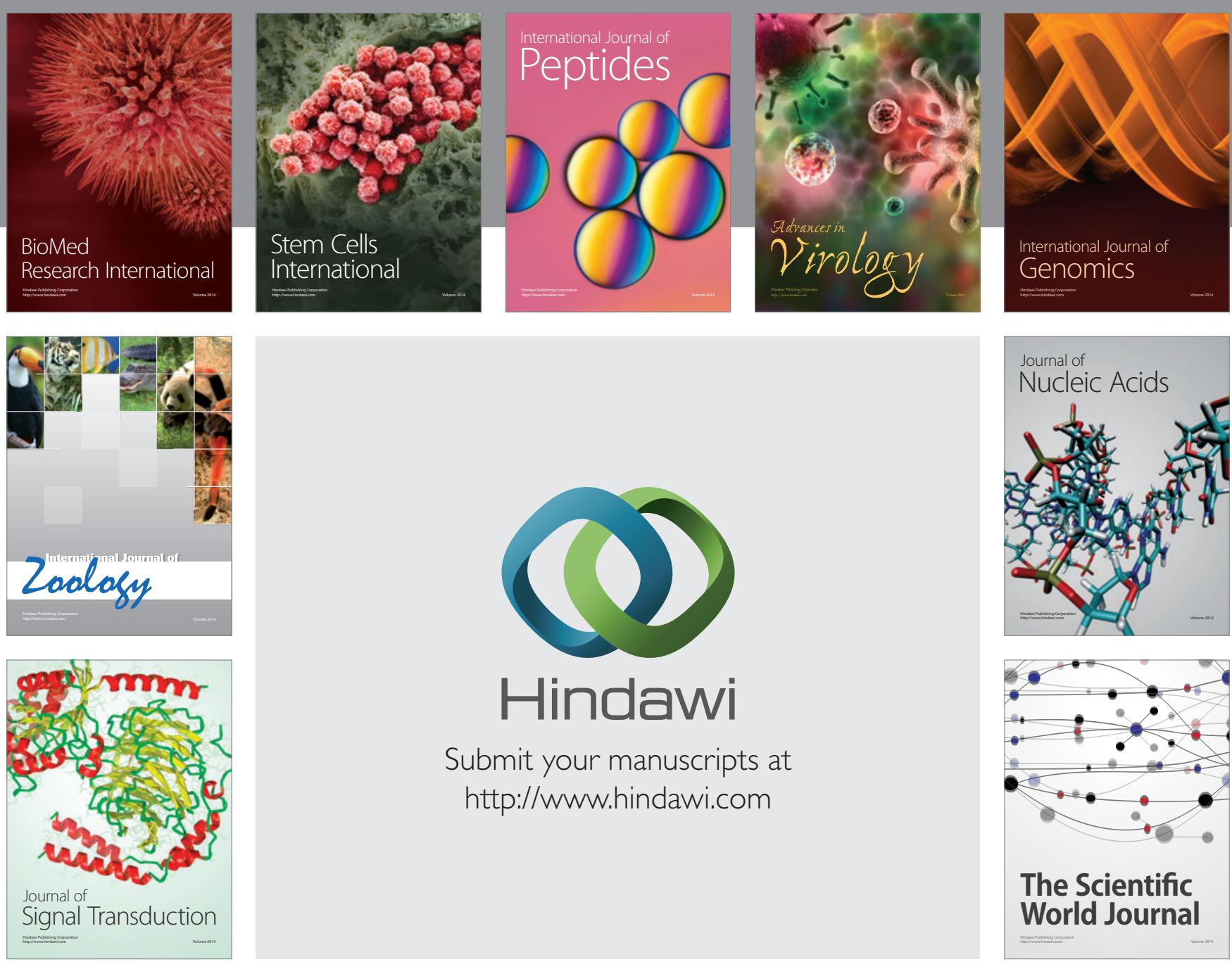

Submit your manuscripts at

http://www.hindawi.com
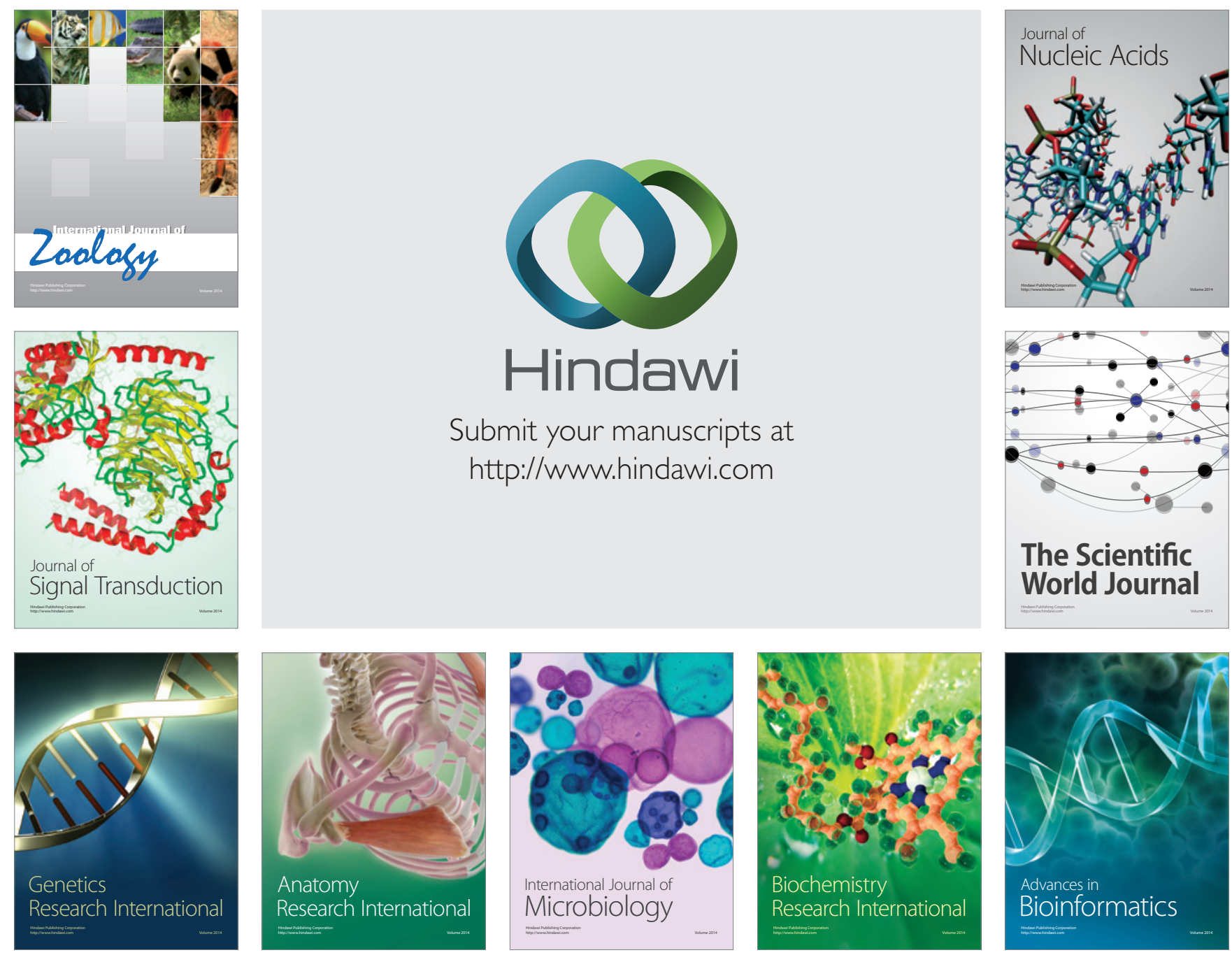

The Scientific World Journal
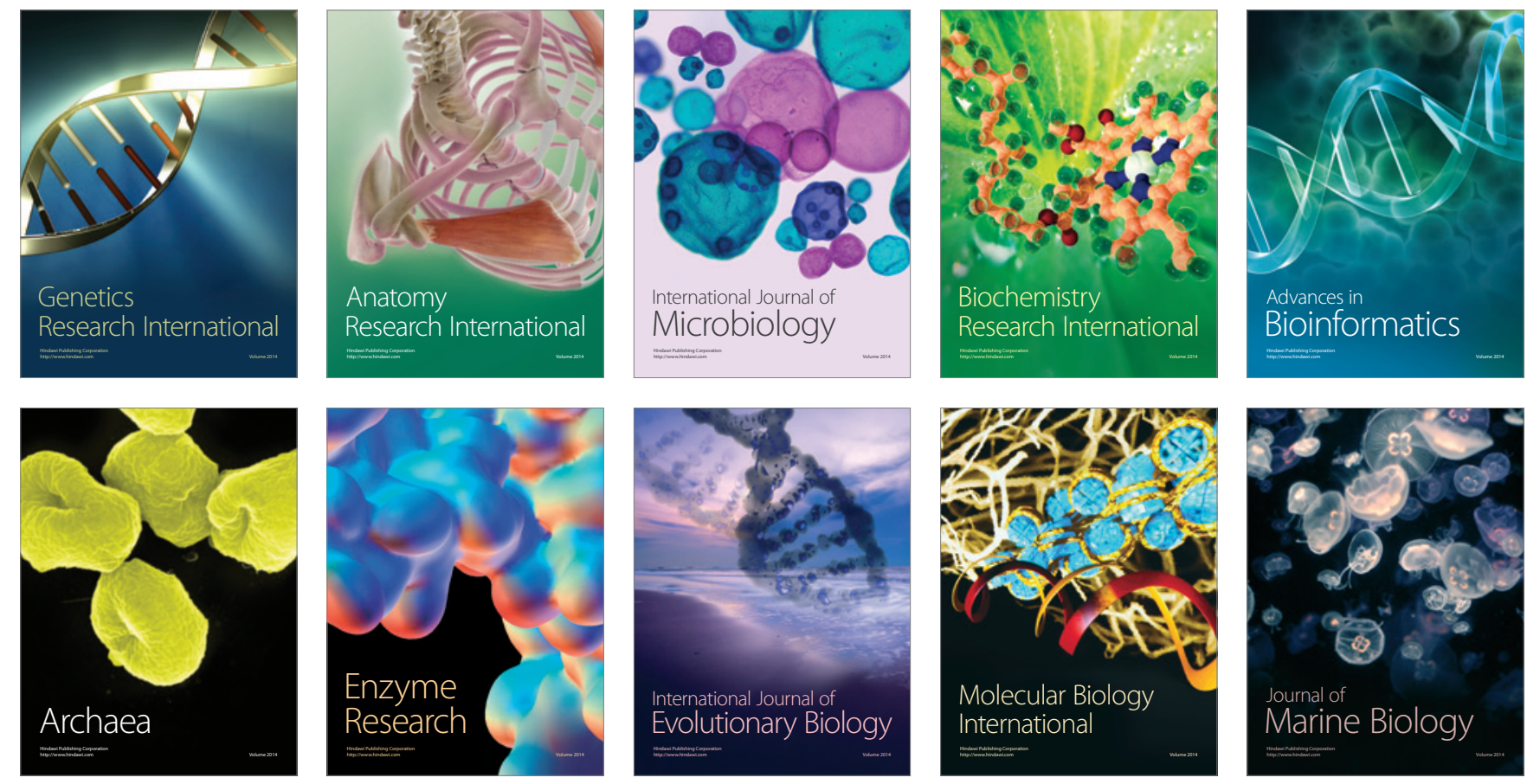